\title{
MENINGKATKAN HASIL BELAJAR MATEMATIKA MELALUI PENERAPAN METODE TEAM GAME TURNAMENT PADA SISWA KELAS VII.1 SMP NEGERI 3 BATANGHARI TAHUN PELAJARAN 2012/2013
}

\author{
Rustinah \\ SMP Negeri 3 Batanghari, Lampung Timur \\ e-mail: rustinah.trida@yahoo.com
}

\begin{abstract}
The aim of this research is to improvestudent's mathematics achievment in aljabar by using TGT method. The research was conducted on SMP N 3 Batanghari. This action research was executed in two cycles, each consisted of one action which was applied in 3-4 meeting with $2 \times 35$ minutes long duration.The analyzed resultof cycle 1 and 2 data observation was: the activity was clearly improved at second cycle by students actively answeres the problem that proposed by the teacher. By the observation data, it clearly showes that implementation of TGT on aljabar competence gave enough significant contribution toward students learning achievment. The result of average data observation was 65,43 with 13 unsuccessful students, with standard classical 66,67\%. On the second cycle, the average score was 69,43 while the number of students who success $70 \%$ with 9 students who field. Although the result was not significant, it's enough to prove that there is student's learning achievement. The 3,33\% improvement still make the researcher smile because the aljabar material is more difficult than other. Beside that problem, the average score of the class which reached 69,35 was difficult to be fulfilled, but by using TGT method, the score can be reached.
\end{abstract}

Keywords: TGT Method, Aljabar, dan Achievment

\section{PENDAHULUAN}

Mutu pendidikan sangat erat kaitannya dengan mutu guru. Kunci keberhasilan pelaksanaan sangat ditentukan oleh faktor guru sebagai pengelola kegiatan pembelajaran. Namun semua juga tidak terlepas dari kemampuan siswa dari proses pembelajaran berlangsung, dari proses belajar mengajar ini harus kerja sama antara guru dengan murid ini akan menghasilkan hasil yang maksimal dengan meminimalkan kendala yang ada dengan memaksimalkan keunggulan dari keduanya.

Untuk mencapai tujuan ini peranan guru sangat menentukan. Menurut Wina Sanjaya (2009 : 19), peran guru adalah: "Sebagai sumber belajar, fasilitator, pengelola, demonstrator, pembimbing, dan evaluator" 
Sebagai motivator guru harus mampu membangkitkan motivasi siswa agar aktivitas siswa dalam proses pembelajaran berhasil dengan baik. Salah satu cara untuk membangkitkan aktivitas siswa dalam proses pembelajaran adalah dengan mengganti cara / model pembelajaran yang selama ini tidak diminati lagi oleh siswa, seperti pembelajaran yang dilakukan dengan ceramah dan tanya-jawab, model pembelajaran ini membuat siswa jenuh dan tidak kreatif. Suasana belajar mengajar yang diharapkan adalah menjadikan siswa sebagai subjek yang berupaya menggali sendiri, memecahkan sendiri masalahmasalah dari suatu konsep yang dipelajari, sedangkan guru lebih banyak bertindak sebagai motivator dan fasilitator. Situasi belajar yang diharapkan di sini adalah siswa yang lebih banyak berperan (kreatif).

Matematika sebagai salah satu bidang studi yang memiliki tujuan membekali siswa untuk mengembangkan penalarannya di samping aspek ilmu pasti banyak memuat materi bersifat hitungan sehingga pengetahuan dan informasi yang diterima siswa lebih banyak dengan menggunakan perhitungan. Sifat materi pelajaran Matematika tersebut membawa konsekuensi terhadap proses belajar mengajar yang didominasi oleh pendekatan ekspositoris, biasanya guru menggunakan metode ceramah maupun tanya jawab terjadi dialog imperatif. Padahal dalam proses belajar mengajar keterlibatan siswa secara totalitas, artinya melibatkan pikiran, penglihatan, pendengaran dan psikomotor (keterampilan, salah satunya sambil menulis). Jadi dalam proses belajar mengajar, seorang guru harus mengajak siswa untuk mendengarkan, menyajikan media yang dapat dilihat, memberi kesempatan untuk menulis dan mengajukan pertanyaan atau tangapan, sehingga terjadi dialog kreatif yang menunjukkan proses belajar mengajar yang interaktif. Situasi belajar ini dapat tercipta melalui penggunaan pendekatan Teams Games Tournaments (TGT). Komponen-komponen dalam TGT adalah penyajian materi, tim, game, turnamen, dan penghargaan kelompok" (Shoimin, 2015:204). Hasil penelitian dari Yuliana, dkk. (2012) menyimpulkan bahwa pembelajaran dengan penerapan model kooperatif tipe TGT memberi pengaruh yang besar terhadap tingginya hasil belajar siswa.

Pada SMP Negeri 3 Batanghari sejak peneliti mengajar, dalam pembelajaran Matematika, peneliti sering menggunakan model pembelajaran ceramah. Model pembelajaran ini tidak dapat membangkitkan aktivitas siswa dalam belajar. Hal 
ini tampak dari perilaku siswa yang cenderung hanya mendengar dan mencatat pelajaran yang diberikan guru. Siswa tidak mau bertanya apalagi mengemukakan pendapat tentang materi yang diberikan.

Sebagai seorang guru yang professional hendaknya dapat memilih dan menerapkan metode yang efektif agar materi yang dipelajari oleh siswa dapat dMatematikahami dengan baik serta dapat meningkatkan prestasi belajar. Lebih menarik lagi jika pada pembelajaran ditemukan metode dan cara-cara yang baru agar dapat terjadi interaksi yang menarik antara siswa dengan guru. Diantara cara dan metode yang digunakan dengan menggunakan sarana yang ada di sekolah diantaranya TGT (Teams Games Tournaments) dengan menggunakan turnamen games akademik yang mana siswa bersaing sebagai perwakilan home team (tum rumah) dengan anggota tim lain.

$\begin{array}{lrr}\text { Dalam } & \text { proses } & \text { belajar } \\ \text { mengajar di sekolah, } & \text { siswa } \\ \text { kelihatan belum serius } & \text { dalam }\end{array}$ mengikuti pelajaran, motivasi belajar Matematika masih kurang, kurang memiliki bekal yang cukup untuk mengikuti kegiatan belajar di sekolah hal ini dapat dibuktikan dengan sering guru memberi pertanyaan pada akhirnya guru sendiri yang menjawab. Hal tersebut terlihat bahwa pelajaran didominasi oleh guru dan penjelasan guru kurang didukung dengan alat peraga yang sesuai dan menarik perhatian siswa. Dari kondisi ini perlu mendapatkan perhatian yang serius dari guru, perbaikan pembelajaran itu dapat dimulai dari diri guru yaitu dengan melakukan perbaikan dengan memperbaiki metode belajar, media, dan sistem belajar mengajar. Dari diri siswa dengan menumbuhkan motivasi belajar siswa.

Banyak siswa kurang berminat terhadap mata pelajaran Matematika karena dianggap sebagai pelajaran yang kurang menyenangkan, akibatnya materi yang sebenarnya mudah menjadi sulit untuk siswa. Berdasarkan latar belakang masalah, dapat diidentifikasi kendala - kendala yang ada di lapangan dalam proses pembelajaran, sehingga prestasi belajar Matematika masih masuk dalam kategori rendah. Dari kendala - kendala tersebut dapat diidentifikasi sebagai berikut: siswa kurang memperhatikan dalam pembelajaran, siswa kurang berani dalam mengemukakan pendapat, siswa beranggapan bahwa dalam belajar kelompok tidak perlu semua bekerja, adanya siswa yang suka membicarakan hal lain, yang tidak berhubungan dengan tugas kelompok, tanggung jawab siswa terhadap kewajiban masih rendah, anggapan bahwa pelajaran Matematika itu sulit, nilai pelajaran matematika cenderung rendah, guru 
mendominasi pelajaran dan guru belum menggunakan metode dan alat peraga yang sesuai.

Berangkat dari masalah masalah yang sangat mengganggu dan menghambat siswa yang bersangkutan untuk meraih prestasi yang lebih tinggi, maka penulis mengadakan perbaikan pembelajaran untuk meningkatkan penguasaan terhadap mata pelajaran Matematika pada diri siswa.

\section{METODE PENELITIAN}

Penelitian ini dilakukan di SMP Negeri 3 Batanghari kecamatan Batanghari kabupaten Lampung Timur. Adapun subyek penelitian adalah siswa kelas VII.1 SMPN 3 Batanghari Semester Ganjil tahun 2012/2013, sebanyak 30 siswa. Penelitian dilaksanakan pada semester ganjil tahun ajaran 2012/2013. Materi yang digunakan dalam penelitian ini adalah materi aljabar.

Prosedur penelitian terdiri atas 4 tahap : yakni tahap perencanaan tindakan, pelaksanaan tindakan, pengamatan dan refleksi pada setiap siklusnya dan berulang kembali pada siklus berikutnya, mengacu model Hopkins dalam bukunya A Teacher's Guide to Classroom Research $2^{\text {nd }}$ Edition (1993: 91) dengan modifikasi (dalam Kusumah dan Dwitagama, 2009: 44) yang di adaptasi untuk dua siklus seperti pada gambar 1 .

Dalam melaksanakan penelitian tindakan kelas digunakan beberapa perangkat penelitian yaitu rencana pembelajaran dan media pembelajaran. Instrumen yang digunakan berupa lembar observasi untuk mengungkap aktivitas siswa dalam proses pembelajaran dan soal tes

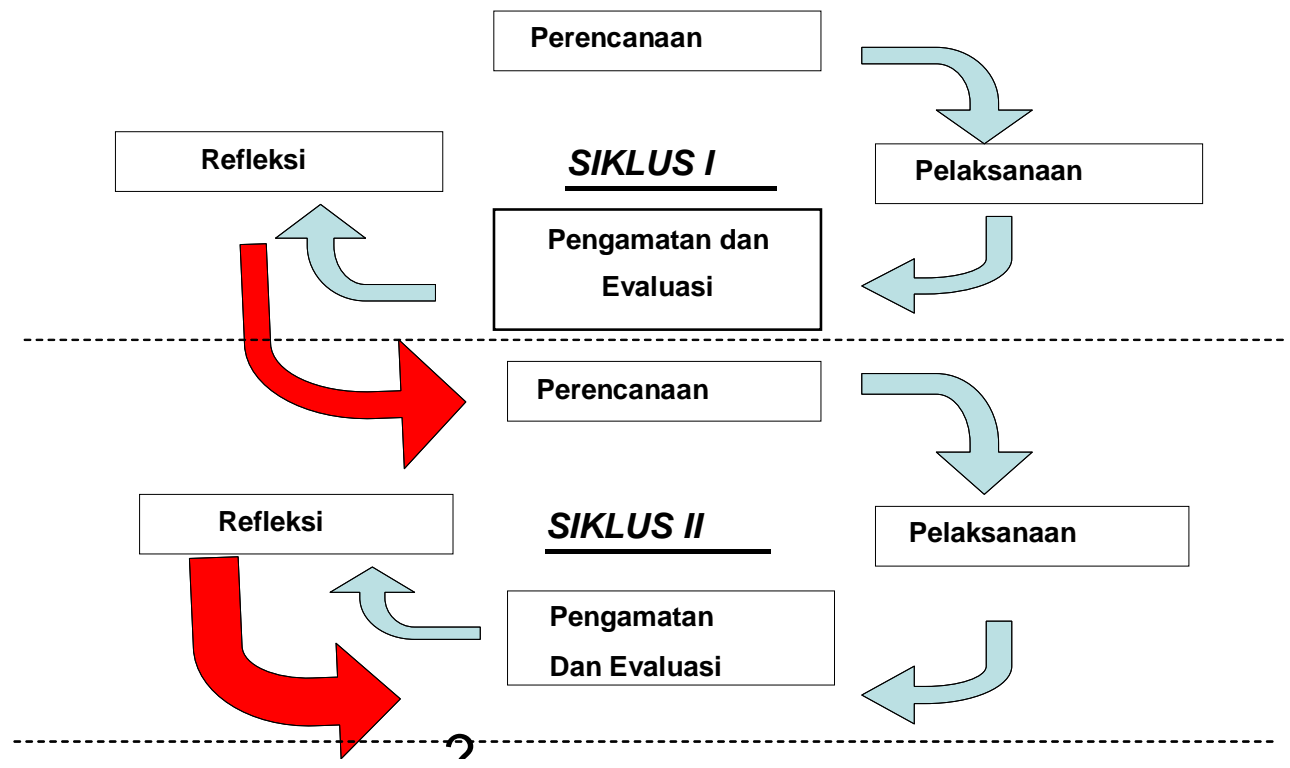

Gambar 1. Siklus Penelitian Tindakan Model Hopkins 
berbentuk pilihan ganda dan uraian untuk mengetahui hasil belajar siswa. Dari hasil tes pada siklus satu dan dua dapat ditarik kesimpulan ada tidaknya peningkatan hasil tes yang dilaksanakan. Data yang diperoleh dari hasil ulangan siswa digunakan untuk mengetahui hasil ketuntasan klasikal maupun individual.

Data aktivitas siswa adalah data kegiatan siswa dalam proses pembelajaran selanjutnya diobservasi dengan mengkaitkannya dalam kategori; Baik, Cukup, Kurang. Indikator observasi ini meliputi; kemampuan menjawab soal dalam game, pemahaman terhadap soal, dan kemampuan dalam menjelaskan setiap soal.

Data hasil tes adalah data yang diperoleh oleh peneliti setelah melakukan tes formatif terhadap siswa setelah pembelajaran. Tes belajar siswa dilakukan selama 2 (dua) kali, pada setiap siklus yang dilakukan. Dari hasil tes pada siklus satu dan dua nantinya akan dibandingkan sehingga dapat ditarik kesimpulan ada tidaknya peningkatan hasil tes yang dilaksanakan. Data yang diperoleh dari hasil ulangan siswa digunakan untuk mengetahui hasil ketuntasan klasikal maupun individual. Ketuntasan individiual ditentukan dengan ketentuan: Adapun rumusan yang digunakan di dalam ketuntasan belajar adalah sebagai berikut :
Ketuntasan secara klasikal, Rumus persentase ketuntasan :

Jumlah Siswa Tuntas x $100 \%$

Ketuntasan belajar individu dinyatakan tuntas apabila tingkat persentase ketuntasan minimal mencapai nilai 65 , sedangkan untuk tingkat klasikal minimal mencapai $75 \%$ (Depdikbud, 1994).

\section{HASIL PENELITIAN DAN PEMBAHASAN}

Penelitian tindakan kelas ini dilakukan dalam dua siklus, meningat banyaknya siswa yang ada dalam kelas VII.1 sehingga tiap siklusnya terdiri dari satu tindakan yang diwujudkan dalam 3-4 kali pertemuan pembelajaran yang lamanya 2 x 35 menit. Jadi pada penelitian tindakan kelas ini diadakan proses pembelajaran sebanyak 8 - 10 kali pertemuan, dengan alokasi waktu 2 kali pertemuan untuk evaluasi.

Pelaksanaan siklus I, Game diawali dengan mempertemukan siswa peringkat 1 sampai dengan 5 , yang semuanya merupakan wakil dari masing-masing kelompok yang telah di bentuk sebelumnya. Dengan jumlah soal sebanyak 2 butir pertanyaan. pada Kartu soal adalah: 
Bentuk sederhan $\frac{3 x^{2}-13 x-10 \text { adalah.... }}{9 x^{2}-4}$.

Yang berhasil di jawab oleh kelompok 2 yang diwakili oleh Annisa Nursetyi, sementara pada Kartu soal ke 2, pertanyaannya adalah :

Bentuk paling
sederhana $\frac{2 x^{2}-5 x-12}{4 x^{2}-9}$ adalah. dari

Yang berhasil di jawab oleh kelompok 1 yang diwakili oleh Nila Selviana sementara pada game 1, kelompok 2 dan 3 masih unggul. Game dilakukan sampe game ke-6. Game yang sudah dilangsungkan merupakan alat untuk mencapai tujuan pembelajaran dengan maksud agar siswa lebih faham dan mengerti, adanya evaluasi merupakan alat ukur sejauh mana pemahaman siswa tentang materi tersebut. Alhasil pada evaluasi siklus II diperoleh hasil pada tabel 1 (nilai KKM adalah 65).

Merupakan hal yang mengejutkan bagi peneliti ketika melihat rata-rata kelas yang termasuk dalam kategori baik, mencapai 65,43, dengan kata lain peneliti cukup puas dengan hasil evaluasi siklus pertama ini, menyisakan 13 orang siswa yang belum tuntas, sedangkan 17 siswa lainnya tuntas.
Tabel 1. Hasil Evaluasi Siklus I

\begin{tabular}{|c|c|c|}
\hline No & Nilai & Ket \\
\hline 1 & 72 & TUNTAS \\
\hline 2 & 70 & TUNTAS \\
\hline 3 & 63 & TIDAK TUNTAS \\
\hline 4 & 80 & TUNTAS \\
\hline 5 & 60 & TIDAK TUNTAS \\
\hline 6 & 73 & TUNTAS \\
\hline 7 & 55 & TIDAK TUNTAS \\
\hline 8 & 56 & TIDAK TUNTAS \\
\hline 9 & 76 & TUNTAS \\
\hline 10 & 76 & TUNTAS \\
\hline 11 & 53 & TIDAK TUNTAS \\
\hline 12 & 76 & TUNTAS \\
\hline 13 & 70 & TUNTAS \\
\hline 14 & 66 & TUNTAS \\
\hline 15 & 60 & TIDAK TUNTAS \\
\hline 16 & 67 & TUNTAS \\
\hline 17 & 60 & TIDAK TUNTAS \\
\hline 18 & 60 & TIDAK TUNTAS \\
\hline 19 & 82 & TUNTAS \\
\hline 20 & 76 & TUNTAS \\
\hline 21 & 45 & TIDAK TUNTAS \\
\hline 22 & 79 & TUNTAS \\
\hline 23 & 66 & TUNTAS \\
\hline 24 & 68 & TUNTAS \\
\hline 25 & 53 & TIDAK TUNTAS \\
\hline 26 & 60 & TIDAK TUNTAS \\
\hline 27 & 70 & TUNTAS \\
\hline 28 & 53 & TIDAK TUNTAS \\
\hline 29 & 72 & TUNTAS \\
\hline 30 & 67 & TUNTAS \\
\hline JUMLAH & & 1963 \\
\hline Rata -rata & & 65.43 \\
\hline
\end{tabular}


Mengacu pada indikator keberhasilan yang mengharapkan bahwa ketuntasan klasikal mencapai angka 75\%, dengan meyisakan $13 \quad(43,33 \%)$ orang siswa yang belum tuntas, dan 66, $67 \%$ siswa tuntas, mau tidak mau penelitian ini akan menitik beratkan untuk mencapai ketuntasan belajar klasikal.

Pada tahap refleksi, beberapa hal yang ditangkap dalam kegiatan ini, adanya dominasi dari siswa yang memang secara kemampuan sudah lebih dibandingkan yang lain, dengan kata lain siswa siswa yang memang peringkat mendominasi, kurang menariknya permainan ( game ) ketika mempertemukan siswa yang memang secara kemampuan rendah. Selain itu tingkat kesulitan soal nampaknya menjadi masalah pada evaluasi siklus I, karena pada soal siklus I hanya menempatkan 2 soal penjumlahan pecahan dan sisanya hanya bentuk soal sedehanakan dan jabarkan.

Pelaksanaan siklus II, Pada fase ini merupakan perbaikan perbaikan dari siklus I, dimana kelemahan pada siklus I menjadi prioritas utama, selain dari meningkatnya kemampuan siswa. Kartu soal disusun oleh guru dan disesuaikan dengan kemampuan siswa, berdasarkan peringkat. Ke2, menjadikan Nila Selviana sebagai Nara sumber dari semua kelompok, karena peneliti menganggap siswa ini telah mampu memahami materi. Sehingga hanya menyisakan 29 siswa yang dibagi kedalam 5 kelompok. Dengan teknik dan prosedur yang sama pada siklus I.

Game diawali dengan mempertemukan siswa peringkat 2 sampai dengan 6 , yang semuanya merupakan wakil dari masingmasing kelompok yang telah di bentuk sebelumnya. Dengan jumlah soal sebanyak 2 butir pertanyaan. pada Kartu soal adalah

Bentuk $\frac{4 x^{2}-13 x-10}{4 x^{2}-4}$ adalah... a

Yang berhasil di jawab oleh kelompok 3 yang diwakili oleh Elsa Anggistiana, sementara pada Kartu soal ke 2, pertanyaannya adalah :

Bentuk
paling
sederhan a dari

Yang berhasil di jawab oleh kelompok 2 yang diwakili oleh Annisa Nursetyani, sementara pada game 1, kelompok 2 masih unggul.

Pada Game ke -2, merupakan game yang mempertemukan siswa yang memilik peringkat 7 sampai dengan 11, sama halnya pada game pertama, kartu soal terdiri atas 2 butir soal yang diperebutkan oleh 6 kelompok.

\section{Hasil dari $(3 a-2 b)(2 a+$ b) adalah....}


2. Hasil dari $2(2 x-4)-3 x+$ 6 adalah...

Dari kedua pertanyaan tersebut, pada pertanyaan pertama, berhasil dijawab oleh kelompok 5 , yang diwakili oleh Rina Ayu puspita sari, sementara pada butir pertanyaan ke -2 berhasil dijawab oleh kelompok 3 yang diwakili oleh Ice Mala Sari. Sehingga pada game ke-2 ini kelompok 2 memimpin.

Game ke $\quad-3$

mempertemukan siswa yang berperingkat 12 sampai dengan peringkat 16, soal yang dperebutkan pada game ini adalah: Soal pertama game ke -3: Jika $4 \boldsymbol{x}$ $+7=6 x-11$, maka nilai $x+3$ adalah...., tidak mampu dijawab oleh peserta, sehingga menjadi pertanyaan lemparan untuk siswa yang lainnya. Dan pertanyaan ini berhasil dijawab oleh Clarisa Wulandari yang merupakan perwakilan kelompok 4, sedangkan pada pertanyaan ke-2 pada game ke -3 ini adalah :

Berhasil dijawab oleh kelompok 1, Ahmad Reza Saputra.

Game

ke-4

mempertemukan siswa yang berperingkat 17 sampai dengan peringkat 23, soal yang dperebutkan pada game ini adalah: Soal pertama game ke -4 : Pemfaktoran dari $4 x^{2}-9 y^{2}$ adalah.... dijawab oleh peserta, asal kelompok 5, yakni M. Azis Sidiq, sedangkan pada pertanyaan ke-2 pada game ke -4 adalah: Hasil dari $(2 x-4)(3 x+5)=\ldots .$. dijawab oleh kelompok 3, Anton Yulianto

Memasuki Team Game tournament sesi ke - 5, dengan mempertemukan siswa yang berada pada peringkat $24-30$, dengan memperebutkan 2 butir soal yang telah dipilih oleh perwakilan siswa. Adapun butir pertanyaan pada kartu soal untuk sesi ke -5 ini adalah :

$\left(2 x^{2}-3 x+2\right)+\left(4 x^{2}-5 x+1\right)$

$\left(3 a^{2}+5\right)-\left(4 a^{2}-3 a+2\right)$

Soal pada sesi ke-5 belum dapat dijawab oleh anggota siswa yang bertanding pada meja game, sehingga dilempar kepada anggota kelompok yang lainnya dan di jawab oleh kelompok 2, atas nama Annisa Nursetyani, untuk butir soal pertama, sedangkan untuk butir soal ke-2 tidak ada yang mampu menjawab.

Sehingga sampai saat ini sudah terdapat 2 butir soal yang tidak mampu dijawab oleh siswa, dan ini menjadi pedoman dalam penyampaian materi pada siklus ke-2 terhadap materi yang belum mampu difahami oleh seluruh siswa.

Perjalanan Game pada siklus II, amat sangat menarik perhatian peneliti, motivasi siswa mengalami peningkatan, pengamatan yang sangat jelas adalah, ketika selesai dijawabnya setiap butir pertanyaan untuk team yang bertanding, ternyata serentak semua siswa ikut mencoba berhitung atas pertanyaanpertanyaan tersebut. Meningkatnya 
semangat belajar siswa membuat peneliti optimis atas hasil pembelajaran yang ada, sehingga dengan meningkatnya semangat belajar siswa dapat pula meningkatkan prestasi belajar siswa.

Hasil dari $\frac{5}{3 x}+\frac{3 x+2}{9 x}$ adalah....

Jumlah butir soal sebanyak 10 butir soal dengan memberikan prosentase yang hampir sama antara penyederhanaan bentuk, penjumlahan, pengurang serta penjumlah dan pengurangan pecahan dalam operasi aljabar, membuat evaluasi ini lebih sesuai denga target yang diharapkan. Adapun hasil evaluasi pada siklus II ini dapat dilihat pada tabel 2 (nilai KKM 65).

Kemampuan

dalam menerapkan serta memotivasi siswa merupakan kunci utama dalam pembelajaran ini, membuat siswa untuk dapat lebih bersemanga, sehingga pembelajaran pun akan semakin menyenangkan dan mengasikan. Game Tournament merupak strategi yang mengasikan dan menyenangkan, selain terjadi persaingan yang positif antar siswa, keberadaan siswa yang memiliki kemampuan dan pemahaman lebih dalam kelompok ternyata mampu untuk mengangkat motivasi rekan yang lainnya.
Tabel 2. Hasil evaluasi siklus II

\begin{tabular}{|c|c|c|}
\hline No & Nilai & Ket \\
\hline 1 & 72 & TUNTAS \\
\hline 2 & 70 & TUNTAS \\
\hline 3 & 63 & TIDAK TUNTAS \\
\hline 4 & 80 & TUNTAS \\
\hline 5 & 60 & TIDAK TUNTAS \\
\hline 6 & 73 & TUNTAS \\
\hline 7 & 55 & TIDAK TUNTAS \\
\hline 8 & 56 & TIDAK TUNTAS \\
\hline 9 & 76 & TUNTAS \\
\hline 10 & 76 & TUNTAS \\
\hline 11 & 60 & TIDAK TUNTAS \\
\hline 12 & 76 & TUNTAS \\
\hline 13 & 75 & TUNTAS \\
\hline 14 & 70 & TUNTAS \\
\hline 15 & 60 & TIDAK TUNTAS \\
\hline 16 & 70 & TUNTAS \\
\hline 17 & 68 & TUNTAS \\
\hline 18 & 68 & TUNTAS \\
\hline 19 & 90 & TUNTAS \\
\hline 20 & 80 & TUNTAS \\
\hline 21 & 50 & TIDAK TUNTAS \\
\hline 22 & 79 & TUNTAS \\
\hline 23 & 66 & TUNTAS \\
\hline 24 & 68 & TUNTAS \\
\hline 25 & 70 & TUNTAS \\
\hline 26 & 60 & TIDAK TUNTAS \\
\hline 27 & 80 & TUNTAS \\
\hline 28 & 65 & TIDAK TUNTAS \\
\hline 29 & 72 & TUNTAS \\
\hline 30 & 75 & TUNTAS \\
\hline Jumlah & 2083 & \\
\hline Rata -rata & 69.43 & \\
\hline
\end{tabular}

Data yang telah diperoleh dari hasil pengamatan pada Siklus I dan Siklus II diolah dan di 
analisis dengan hasil sebagai berikut :

1. Aktifitas jelas semakin meningkat pada siklus II, dengan ikut sertanya audiens ( siswa yang tidak bertanding ) dalam mencoba berhitung terhadap setiap soal yang di ajukan oleh guru.

2. Dari data penilaian evaluasi jelaslah bahwa implementasi pembelajaran dengan menggunakan model Team game Tournament pada Kompetensi dasar Melakukan operasi Aljabar, memberikan kontribusi yang cukup signifikan (positif) terhadap peningkatan prestasi belajar siswa. hal ini terlihat dari siklus ke-1 ke siklus ke-2 tampak pada tabel diatas pada siklus ke-1 pada hasil evaluasi nilai ratarata kelas yang diperoleh adalah 65,43 , dengan siswa yang belum tuntas sebanyak 13 orang siswa, dengan ketuntasan klasikal 66,67\%, pada siklus II rata-rata kelas yang diraih adalah 69,43, sedangkan jumlah siswa yang tuntas mencapai $70 \%$. Menyisakan sebanyak 9 orang siswa yang belum tuntas. meskipun tidak signifikan secara peningkatan hasil belajar hal ini cukup membuktikan adanya peningkatan prestasi belajar siswa dalam pembelajaran.

3. Peningkatan yang hanya $3,33 \%$ ini tetap dapat membuat peneliti sedikit tersenyum, karena operasi aljabar merupakan materi yang sedikit sulit dibandingkan materi yang lainnya, selain hal tersebut angka rata-rata kelas yang mencapai 69,35 untuk pelajaran matematika merupakn angka yang sulit untuk dicapai. Tetapi dengan penerapan metode TGT angka tersebut ternyata mampu diraih.

4. Dengan memperhatikan indikator keberhasilan yang ada bahwa penelitian ini dinyata kan berhasil secara klasikal apabila mencapai angka $75 \%$ siswa tuntas, berdasarkan hasil yang ada maka penelitian ini Masih belum berhasil.

Tabel 3. Hasil Siklus I dan II

\begin{tabular}{|c|c|c|}
\hline No & $\begin{array}{c}\text { SIKLUS } \\
\text { I }\end{array}$ & $\begin{array}{c}\text { SIKLUS } \\
\text { II }\end{array}$ \\
\hline 1 & 72 & 72 \\
\hline 2 & 70 & 70 \\
\hline 3 & 63 & 63 \\
\hline 4 & 80 & 80 \\
\hline 5 & 60 & 60 \\
\hline 6 & 73 & 73 \\
\hline 7 & 55 & 55 \\
\hline 8 & 56 & 56 \\
\hline 9 & 76 & 76 \\
\hline 10 & 76 & 76 \\
\hline 11 & 53 & 60 \\
\hline 12 & 76 & 76 \\
\hline 13 & 70 & 75 \\
\hline 14 & 66 & 70 \\
\hline
\end{tabular}




\begin{tabular}{|c|c|c|}
\hline 15 & 60 & 60 \\
\hline 16 & 67 & 70 \\
\hline 17 & 60 & 68 \\
\hline 18 & 60 & 68 \\
\hline 19 & 82 & 90 \\
\hline 20 & 76 & 80 \\
\hline 21 & 45 & 50 \\
\hline 22 & 79 & 79 \\
\hline 23 & 66 & 66 \\
\hline 24 & 68 & 68 \\
\hline 25 & 53 & 70 \\
\hline 26 & 60 & 60 \\
\hline 27 & 70 & 80 \\
\hline 28 & 53 & 65 \\
\hline 29 & 72 & 72 \\
\hline 30 & 67 & 75 \\
\hline JUMLAH & 1963 & 2083 \\
\hline Rata-rata & 65.43 & 69.43 \\
\hline & & \\
\hline
\end{tabular}

dasar melakukan operasi Aljabar untuk siswa kelas VII. 1 SMPN 3 Batanghari. Terbukti terdapat meningkatkan prosentase jumlah siswa yang tuntas dari siklus I sebesar $66,67 \%$ menjadi $70 \%$ pada siklus II, atau mengalami peningkatan sebesar 3,33\%

3. Respon siswa terhadap implementasikan Pembelajaran dengan menggunakan Team Game Tournament Pada Kompetensi dasar melakukan operasi Aljabar untuk siswa kelas VII. 1 SMPN 3 Batanghari. Masih belum berhasil

Berdasarkan kesimpulan di atas maka saran dalam penelitian ini sebagai berikut:

1. Guru dalam pembelajaran ini hendaknya lebih banyak strategi pembelajaran daripada sekedar memberikan informasi.

Berdasarkan hasil penelitian dan pembahasan yang telah penulis kemukakan dalam bab sebelumnya, maka dapat disimpulkan hal-hal sebagai berikut :

1. Pembelajaran dengan menggunakan Team Game Tournament Pada Kompetensi dasar melakukan operasi Aljabar untuk siswa kelas VII. 1 SMPN 3 Batanghari dilakukan dalam 2 (tiga) siklus dengan tanpa hambatan berarti.

2. Pembelajaran dengan menggunakan Team Game Tournament Pada Kompetensi

2. Siswa diberi kesempatan untuk menemukan dan menerapkan ide-idenya, dan guru sebaiknya sebagai fasilitator.

3. Kepala sekolah diharapkan mendukung dan memotivasi guru dalam pelaksanaan penelitian tindakan kelas.

\section{DAFTAR PUSTAKA}

Depdikbud. 1994. Kurikulum SMU Petunjuk Pelaksanaan Proses Belajar Mengajar. Jakarta: Depdikbud Dirjen Dikdasmen Direktorat Pendidikan Menengah Umum. 
Kusumah, Wijaya dan Dwitagama, Dedi. 2009. Mengenal Penelitian Tindakan Kelas. Jakarta: Indeks.

Sanjaya, Wina. 2009. Strategi Pembelajaran: Berorietasi Standar Proses Pendidikan. Jakarta: Prenada Media Group.

Shoimin, Aris. 2015. 68 Model Pembelajaran Inovatif dalam Kurikulum 2013. Yogyakarta: Ar-Ruzz Media.

Yuliana, dkk. 2012. Pengaruh Penerapan TGT Terhadap Hasil Belajar Pada Pembelajaran Matematika Kelas IV SDN 11 Ponkot. Skripsi. Universitas Tanjungpura, (Pontianak. http://jurnal.untan.ac.id/index. php/jpdpb/article/download/11 07/pd 